\title{
The Antipyridoxine Effect of Penicillamine in Man *
}

\author{
Israeli A. Jaffe, Kurt Altman, and Parvin Merryman \\ (From the Department of Internal Medicine, New York Medical College, Nerw York, N. Y.)
}

Penicillamine is a potent oral chelating agent that is used in the treatment of Wilson's disease and certain heavy metal intoxications $(1,2)$. It is currently under study in primary macroglobulinemia, the cold agglutinin syndrome, rheumatoid arthritis, and cystinuria (3-6). It has been well established that L-penicillamine exerts an antivitamin $\mathrm{B}_{6}$ effect in the rat $(7,8)$. This is manifest by growth depression, excessive urinary excretion of xanthurenic acid after a tryptophane load, and a reduced activity of the pyridoxine-dependent alanine-glutamic (G.P.T.) and asparticglutamic (G.O.T.) transaminases. All of these effects were reversed by the simultaneous administration of vitamin $\mathrm{B}_{6}$. D-Penicillamine was not growth inhibitory in the rat, hence it has been believed to be devoid of antipyridoxine activity (9).

L-Penicillamine forms a thiazolidine compound with pyridoxal 5-phosphate (10). Since pyridoxal 5-phosphate is the coenzyme of kynureninase (11), its inactivation by L-penicillamine would result in an impairment in the metabolism of tryptophane via the kynurenine pathway (7). Recent studies, however, indicate that D-penicillamine also forms a thiazolidine with pyridoxal 5-phosphate (12); hence it too might be expected to have antivitamin $\mathrm{B}_{6}$ effects.

The increased urinary excretion of the intermediary metabolites of tryptophane (xanthurenic acid and kynurenine) that occurs in patients treated with isoniazid has led to the concept that that drug is a metabolic antagonist of vitamin $\mathrm{B}_{6}$ (13). The co-administration of this vitamin with isoniazid has favorably influenced certain of the toxic manifestations of the drug without impairing its efficacy (14).

DL-Penicillamine has been employed clinically without the apparent development of signs of py-

* Submitted for publication April 21, 1964; accepted June 11, 1964.

Supported by the U. S. Army Medical Research and Development Command (DA-49-193MD-2445), and the Arthritis and Rheumatism Foundation. ridoxine deficiency. Most patients given the drug were treated prophylactically with pyridoxine. Recertly, optic axial neuritis has been described in a patient with Wilson's disease receiving DLpenicillamine alone (15). Administration of vitamin $\mathrm{B}_{6}$ corrected the increased urinary xanthurenic acid excretion after tryptophane loading in this patient and was associated with a clearing of the neuritis.

The $\mathrm{LD}_{50}$ of DL-penicillamine for the rat is 365 $\mathrm{mg}$ per $\mathrm{kg}$ in a single oral dose, whereas $1,200 \mathrm{mg}$ per $\mathrm{kg}$ of $\mathrm{D}$-penicillamine produced no toxic signs (16). The present availability of pure D-penicillamine for clinical use has prompted a study of the effects of this agent, and the racemic mixture, on tryptophane metabolism in man.

\section{Methods}

An abnormal urinary excretion of xanthurenic acid and kynurenine after an oral dose of $5 \mathrm{~g}$ of DL-tryptophane was used as the indicator of pyridoxine deficiency or metabolic blockade $(17,18)$. The tryptophane was administered as a suspension in fruit juice. Twentyfour-hour urine specimens following the loading dose were collected under ice, but without preservative. Xanthurenic acid was determined by the method of Wachstein (normal: 0 to $30 \mathrm{mg}$ per 24 hours), and kynurenine by the method of Tompsett (normal: 10 to $20 \mathrm{mg}$ per 24 hours $)(19,20)$.

Of the nine patients studied, three were convalescent from recent fractures but were otherwise free of organic disease, and six had rheumatoid arthritis. All were ambulatory and were on a regular hospital diet. They were taking no medication during the study periods except the penicillamine and small doses of aspirin as needed. All of the patients received D-penicillamine, $2 \mathrm{~g}$ per 24 hours in four divided doses, for a minimum of 14 days. In three of the patients, it was also possible to study DL-penicillamine on the same regimen. Patient J.S. was given the course of D-penicillamine before the DL, whereas in patients P.E. and D.G., this sequence was reversed. In all instances, tryptophane metabolites had returned to control values before the isomers were changed. One patient, D.G., was placed on isoniazid, $1,200 \mathrm{mg}$ per 24 hours, for 14 days after his courses of penicillamine had been completed. Pyridoxine was always given as the hydrochloride, $100 \mathrm{mg}$ daily, by intramuscular injection. 
TABLE I

The effect on the urinary excretion of the intermediary metabolites of tryptophane induced by 14 days of penicillamine administration

\begin{tabular}{|c|c|c|c|c|c|c|c|c|c|}
\hline \multirow[b]{2}{*}{ Patient } & \multirow[b]{2}{*}{ Diagnosis } & \multicolumn{2}{|c|}{ Control } & \multicolumn{2}{|c|}{$\begin{array}{c}\text { D-Penicillamine } \\
\text { (2 weeks) }\end{array}$} & \multicolumn{2}{|c|}{ Control } & \multicolumn{2}{|c|}{$\begin{array}{l}\text { DL-Penicillamine } \\
\text { (2 weeks) }\end{array}$} \\
\hline & & $\begin{array}{l}\text { Xanthu- } \\
\text { renic } \\
\text { acid }\end{array}$ & $\begin{array}{l}\text { Kynu- } \\
\text { renine }\end{array}$ & $\begin{array}{l}\text { Xanthu- } \\
\text { renic } \\
\text { acid }\end{array}$ & $\begin{array}{l}\text { Kynu- } \\
\text { renine }\end{array}$ & $\begin{array}{l}\text { Xanthu- } \\
\text { renic } \\
\text { acid }\end{array}$ & $\begin{array}{l}\text { Kynu- } \\
\text { renine }\end{array}$ & $\begin{array}{l}\text { Xanthu- } \\
\text { renic } \\
\text { acid }\end{array}$ & $\begin{array}{l}\text { Kynu- } \\
\text { renine }\end{array}$ \\
\hline & & \multicolumn{2}{|c|}{$m g / 24 h r s$} & \multicolumn{2}{|c|}{$m g / 24 h r s$} & \multicolumn{2}{|c|}{$m g / 24 h r s$} & \multicolumn{2}{|c|}{$m g / 24 h r s$} \\
\hline J.T. & Normal & 15 & 18 & 27 & 98 & & & & \\
\hline P.E. & Normal & 9 & 15 & 56 & 49 & 15 & 13 & 243 & 164 \\
\hline B.L. & Normal & 20 & 26 & 88 & 75 & & & & \\
\hline D.G. & Rheumatoid arthritis & 16 & 14 & 11 & 85 & 12 & 20 & 75 & 140 \\
\hline J.S. & Rheumatoid arthritis & 11 & 28 & 47 & 74 & 16 & 24 & 95 & 196 \\
\hline L.W. & Rheumatoid arthritis & 16 & 23 & 88 & 96 & & & & \\
\hline R.B. & Rheumatoid arthritis & 20 & 60 & 60 & 117 & & & & \\
\hline M.M. & Rheumatoid arthritis & 15 & 65 & 85 & 161 & & & & \\
\hline C.P. & Rheumatoid arthritis & 14 & 17 & 97 & 73 & & & & \\
\hline
\end{tabular}

\section{Results}

Table I gives the values for xanthurenic acid and kynurenine obtained before and after 2 weeks of D-penicillamine as well as the comparable data for the DL-isomer in those patients given both forms. All of the nine patients had a significantly increased urinary kynurenine excretion, and eight showed an elevated xanthurenic acid after the course of D-penicillamine. In the three patients who also received the $\mathrm{DL}$-form, an even greater excretion of the intermediary metabolites was found.

Figure 1 illustrates the sequence of events in patient D.G. The administration of pyridoxine with DL-penicillamine appears to have prevented any antimetabolic effect. When the vitamin was

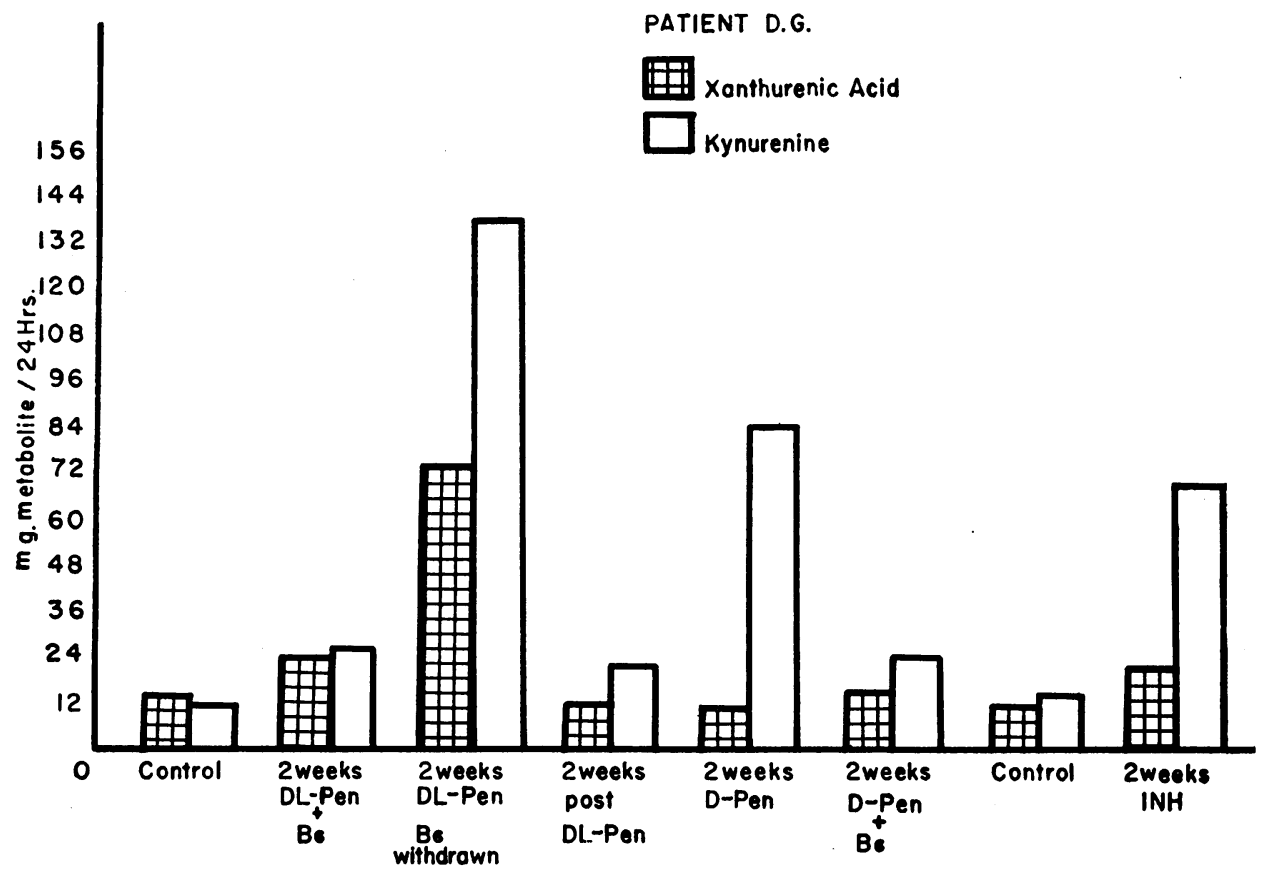

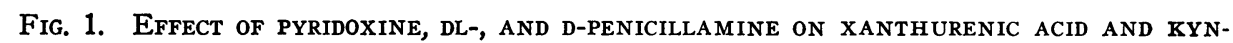
URENINE EXCRETION AFTER A LOADING DOSE OF TRYPTOPHANE. The withdrawal of pyridoxine results in an increase in metabolites induced by DL-penicillamine. D-Penicillamine also produced a significant rise in urinary kynurenine, although less marked than that following the DL, and it too was reversed by the simultaneous administration of vitamin $B_{6}$. 


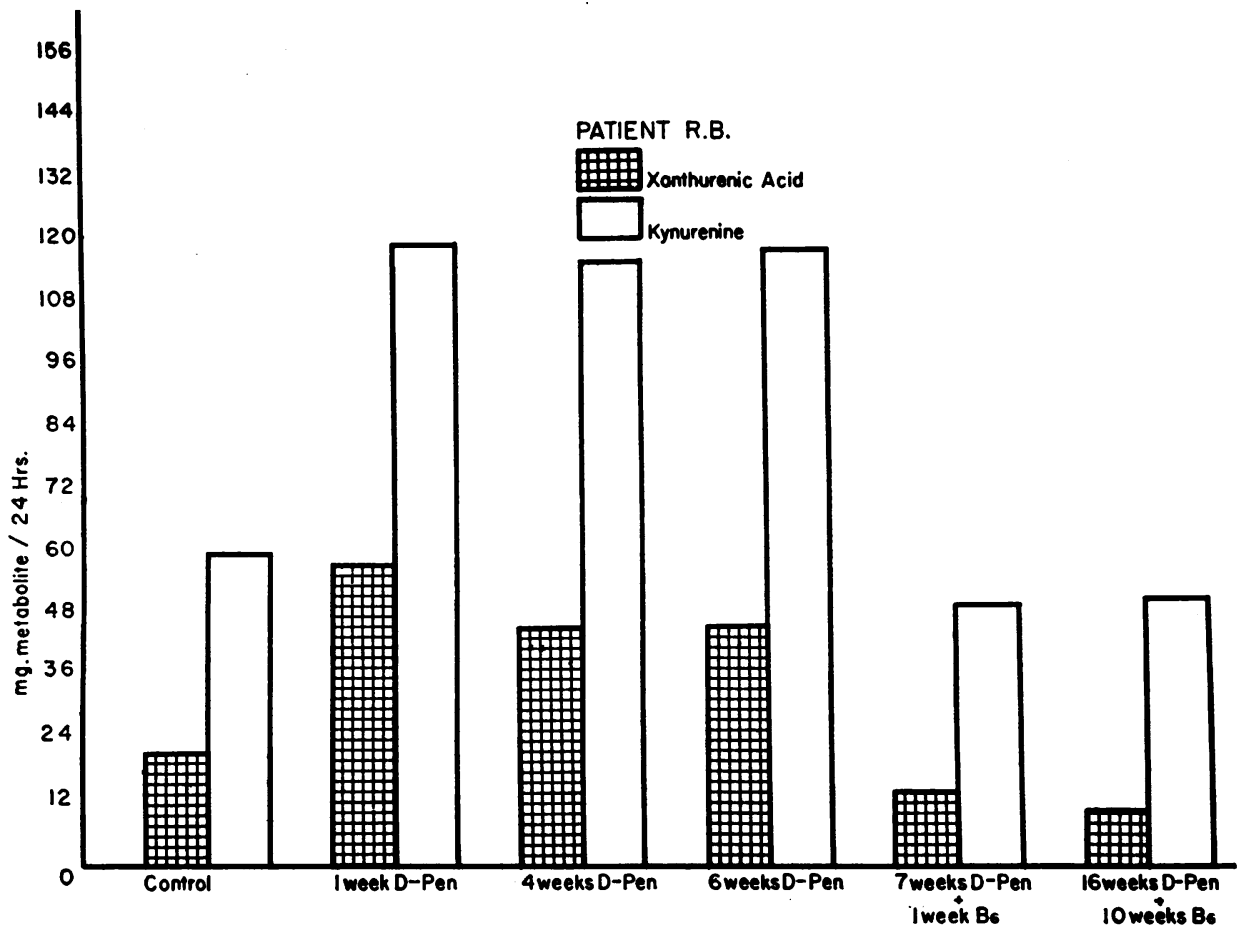

Fig. 2. Pattern of excretion of metabolites during prolonged drug treatment. $1:$ : H The magnitude of the induced defect does not appear to be significantly increased by increased duration of drug administration. The corrective effect of vitamin $B_{6}$ is not lost with time.

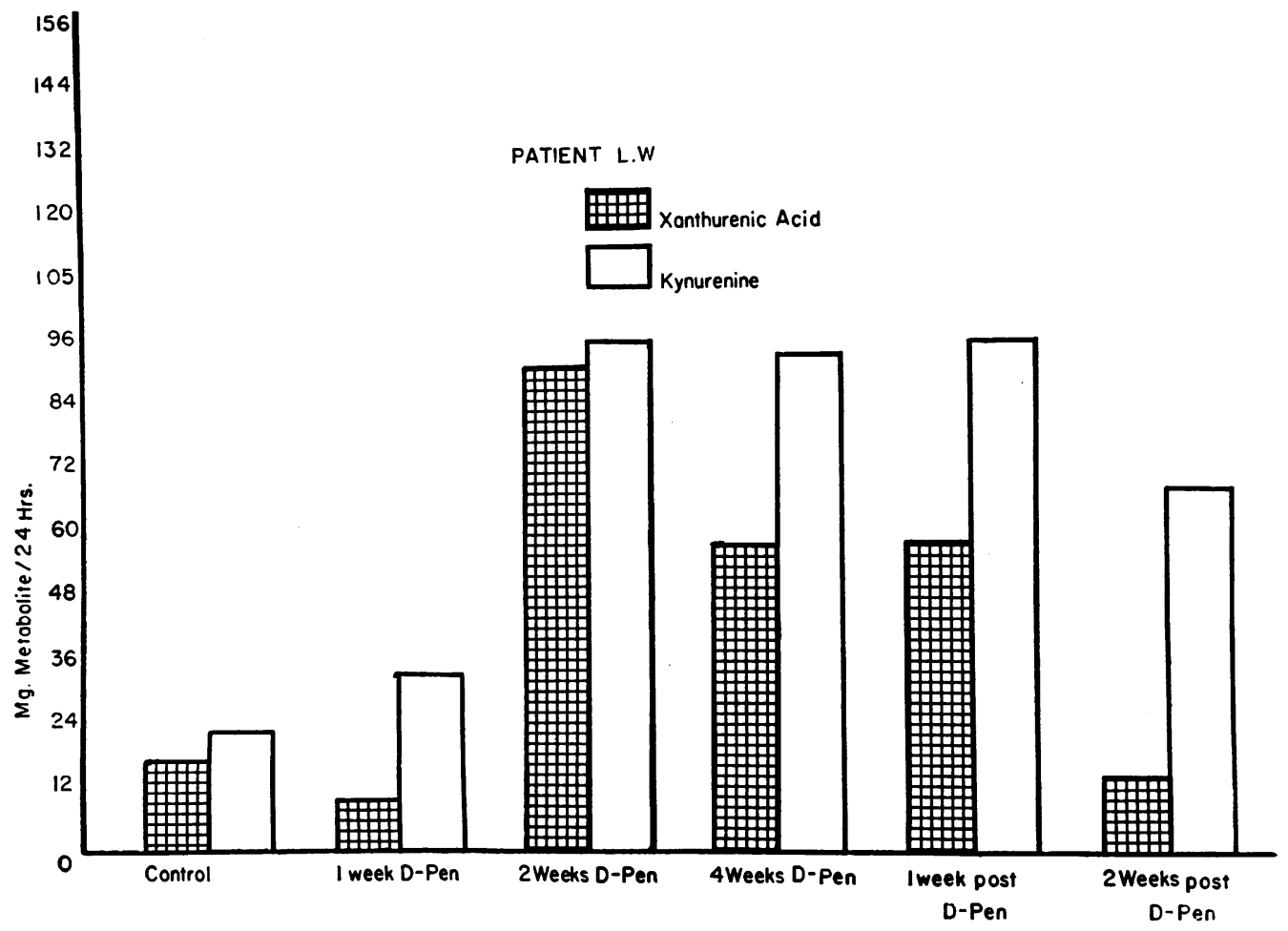

Fig. 3. Persistence of the Defect When Pyridoxine is not added. This patient showed the maximal antimetabolite effect by the second week, and the changes persisted for more than 2 weeks after the drug was discontinued; no $B_{0}$ was added. 
withdrawn and the drug continued for an additional 14 days, a definite rise in the excretion of metabolites occurred. One week after penicillamine was discontinued, the urinary excretion pattern had returned to control values. After 14 days of the D-isomer, this patient showed an increased excretion only of kynurenine. The simultaneous administration of pyridoxine with D-penicillamine reduced the kynurenine excretion to the normal range. Isoniazid, in a dosage of $1,200 \mathrm{mg}$ per 24 hours, exerted approximately the same antipyridoxine effect as $2.000 \mathrm{mg}$ of $\mathrm{D}$-penicillamine in this patient.

The data presented in Figure 2 indicate that prolonged administration of the drug is not associated with a progressive increase in the amount of metabolite excreted. D-Penicillamine resulted in an increased xanthurenic acid and kynurenine excretion in this case. The reversal of the abnormal urinary pattern by the addition of pyridoxine was achieved within the first week and was maintained as long as the vitamin was continued.

In the patient whose response is illustrated in Figure 3 , the abnormality did not become manifest until the second week of D-penicillamine administration, and the changes persisted for more than 2 weeks after the drug was withdrawn. No supplemental pyridoxine was given.

\section{Discussion}

The data presented clearly indicate that $\mathrm{D}$-penicillamine exerts an antagonism to pyridoxine in man, based upon the disturbance induced in the metabolism of a test dose of tryptophane and its reversal by the concomitant administration of the vitamin. Two of the patients with rheumatoid arthritis showed elevated control values for kynurenine. An abnormality in the metabolism of tryptophane has been described in some patients with rheumatoid arthritis (21), but their response to penicillamine here observed was similar to that found in the normal subjects.

The presence of arthritis, therefore, would not invalidate these patients as a suitable study group. Each patient served as his own control, and the antipyridoxine effects induced by the drug were neither masked nor enhanced by the underlying disease. Aspirin has been shown to have no effect on tryptophane metabolism (21), and no other antirheumatic drugs were given.

In those patients in whom a comparison could be made, DL-penicillamine was found to be a greater antagonist than the pure $\mathrm{D}$-isomer in equivalent dosage. The inhibitory effects of the L-enantiomorph in man are consistent with the earlier studies in the rat $(7,8)$. The $\mathrm{D}$-isomer, however, which was not growth inhibitory in animals, has here been shown to exert a definite antipyridoxine effect in man. Species differences and relative dosage might account for this apparent discrepancy in response. The in vivo enzyme studies that demonstrated a depression in rat liver transaminase activity after L-penicillamine were not paralleled by a corresponding investigation of enzyme levels after administration of the $\mathrm{D}$-isomer (22). Despite the absence of growth retardation in the D-penicillamine-treated animals, some impairment in tissue transaminase activity could conceivably have been present. Blood transaminase activity in the rat has also been shown to be inhibited by penicillamine, but again, only the DL-form was studied (23). Finally, the D-penicillamine used in these studies was reanalyzed after the antipyridoxine effect was demonstrated, and the drug was found to be entirely free of contamination with the L-isomer. ${ }^{1}$

The dose of penicillamine used in this study was the same as that which is generally employed clinically. Yet even the D-isomer in this dosage produced a degree of pyridoxine antagonism comparable to 3 to 4 times the usual therapeutic dose of isoniazid, based upon a comparison of the kynurenine excretion levels induced by each drug in the same patient. Studies in the rat suggest that, if extrapolated to man, $50 \mathrm{mg}$ per day of pyridoxine would be required to give near maximal protection against the anti- $\mathrm{B}_{6}$ activity of 1.5 $\mathrm{g}$ of DL-penicillamine (23). In every patient studied here, $100 \mathrm{mg}$ of pyridoxine daily was able to correct the defect as evidenced by a return of the tryptophane metabolites to normal.

Since penicillamine is generally given for prolonged periods without interruption, we conclude on the basis of these findings that pyridoxine supplementation should be part of the therapeutic regimen, even when the D-isomer is used.

${ }^{1}$ Merck Sharp \& Dohme Research Laboratories, Philadelphia, $\mathrm{Pa}$. 


\section{Summary}

The antipyridoxine effect of $\mathrm{D}$ - and DL-penicillamine has been studied in man. An elevation in the 24-hour urinary excretion of xanthurenic acid and kynurenine after a loading dose of tryptophane has been used as the parameter of vitamin $\mathrm{B}_{6}$ antagonism. Both D- and DL-penicillamine have been shown to have an antipyridoxine effect in man, although that induced by the DL-form is considerably greater, as would be expected from previous animal studies. We suggest that pyridoxine supplementation be included in any long term penicillamine therapy, regardless of the isomer that is employed.

\section{References}

1. Walshe, J. M. Treatment of Wilson's disease with penicillamine. Lancet 1960, 1, 188.

2. Ohlsson, W. T. L. Penicillamine as a lead-chelating substance in man. Brit. med. J. 1962, 1, 1454.

3. Ritzmann, S. E., S. L. Coleman, and W. C. Levin. The effect of some mercaptanes upon a macrocryogelglobulin; modifications induced by cysteamine, penicillamine and penicillin. J. clin. Invest. 1960, 39, 1320.

4. Ritzmann, S. E., and W. C. Levin. Effect of mercaptanes in cold agglutinin disease. J. Lab. clin. Med. 1961, 57, 718.

5. Jaffe, I. A. Comparison of the effect of plasmapheresis and penicillamine on the level of circulating rheumatoid factor. Ann. rheum. Dis. 1963, $22,71$.

6. Crawhall, J. C., E. F. Scowen, and R. W. E. Watts. Effect of penicillamine on cystinuria. Brit. med. J. 1963, 1, 588 .

7. Kuchinskas, E. J., and V. du Vigneaud. An increased vitamin $\mathrm{B}_{6}$ requirement in the rat on a diet containing L-penicillamine. Arch. Biochem. 1957, 66, 1.

8. Kuchinskas, E. J., A. Horvath, and V. du Vigneaud. An anti-vitamin $B_{6}$ action of L-penicillamine. Arch. Biochem. 1957, 68, 69.

9. Wilson, J. E., and V. du Vigneaud. Inhibition of the growth of the rat by L-penicillamine and its prevention by aminoethanol and related compounds. J. biol. Chem. 1950, 184, 63.
10. Heyl, D., S. A. Harris, and K. Folkers. The chemistry of vitamin $B_{6}$. VI. Pyridoxylamino acids. J. Amer. chem. Soc. 1948, 70, 3429.

11. Dalgliesh, C. E., W. E. Knox, and A. Neuberger. Intermediary metabolism of tryptophan. Nature (Lond.) 1951, 168, 20.

12. Ueda, K., A. Hitoshi, and S. Masami. Intestinal absorption of amino acids IV. Participation of pyridoxal phosphate in the active transport of L-amino acids through the intestinal wall. $\mathrm{J}$. Biochem. (Tokyo) 1960, 48, 584.

13. Price, J. M., R. R. Brown, and F. C. Larson. Quantitative studies on human urinary metabolites of tryptophan as affected by isoniazid and deoxypyridoxine. J. clin. Invest. 1957, 36, 1600.

14. Carlson, H. B., E. M. Anthony, W. F. Russell, Jr., and G. Middlebrook. Prophylaxis of isoniazid neuropathy with pyridoxine. New Engl. J. Med. 1956, 255, 118.

15. Jun-bi Tu, R. Q. Blackwell, and P.-F. Lee. DL-Penicillamine as a cause of optic axial neuritis. J. Amer. med. Ass. 1963, 185, 83.

16. Aposhian, H. V., and M. M. Aposhian. N-AcetylDL-penicillamine, a new oral protective agent against the lethal effects of mercuric chloride. J. Pharmacol. exp. Ther. 1959, 126, 131.

17. Greenberg, L. D., D. F. Bohr, H. McGrath, and J. F. Rinehart. Xanthurenic acid excretion in the human subject on a pyridoxine-deficient diet. Arch. Biochem. 1949, 21, 237.

18. Jakoby, W. B., and D. M. Bonner. Kynureninase from neurospora: purification and properties. J. biol. Chem. 1953, 205, 699.

19. Wachstein, M., and A. Gudaitis. Detection of vitamin $B_{6}$ deficiency. Amer. J. clin. Path. 1952, 22, 652.

20. Tompsett, S. L. The determination in urine of some metabolites of tryptophane-kynurenine, anthranilic acid and 3-hydroxyanthranilic acid-and reference to the presence of $o$-aminophenol in urine. Clin. chim. Acta 1959, 4, 411.

21. Bett, I. M. Metabolism of tryptophan in rheumatoid arthritis. Ann. rheum. Dis. 1962, 21, 63.

22. Du Vigneaud, V., E. J. Kuchinskas, and A. Horvath. L-Penicillamine and rat liver transaminase activity. Arch. Biochem. 1957, 69, 130.

23. Heddle, J. G., E. W. McHenry, and G. H. Beaton. Penicillamine and vitamin $\mathrm{B}_{6}$ interrelationships in the rat. Canad. J. Biochem. 1963, 41, 1215. 